\title{
The prevalence of contact hypersensitivity in patients with oral lichen planus
}

\author{
Maria Olejnik ${ }^{1}$, Dorota Jenerowicz² ${ }^{2}$ Zygmunt Adamski², Magdalena Czarnecka-Operacz², Barbara Dorocka-Bobkowska ${ }^{1}$ \\ ${ }^{1}$ Department of Gerodontology and Oral Pathology, Poznan University of Medical Sciences, Poznan, Poland \\ ${ }^{2}$ Department of Dermatology, Poznan University of Medical Sciences, Poznan, Poland \\ Adv Dermatol Allergol 2022; XXXIX (4): 668-674 \\ DOI: https://doi.org/10.5114/ada.2021.107549
}

\begin{abstract}
Introduction: Oral lichen planus (OLP) is a chronic autoimmune inflammatory disease with an unknown aetiology and a higher prevalence in women. Oral lichenoid lesions both clinically and histologically resemble oral lichen planus and are often associated with contact allergy to dental materials.

Aim: To investigate the prevalence of delayed hypersensitivity reactions in patients with OLP and to identify the most common allergens that may exacerbate the disease.

Material and methods: Twenty patients diagnosed with OLP and undergoing treatment in the Gerodontology and Oral Pathology Department of the Poznan University of Medical Sciences were enrolled in the study. The subjects underwent a detailed oral examination consisting of anamnesis and a clinical evaluation by a qualified dentist, while an assessment of the skin and skin appendages was carried out by a dermatologist. Patch testing was performed using the Polish Baseline Series and Dental Screening Series.

Results: Fifty percent of the examined patients displayed positive patch test reactions. A total of 18 allergic reactions were revealed, but only four appeared during the first test. The most common allergens were found to be nickel, gold, and a fragrance mix. Only 1 patient had a positive reaction to more than three allergens.

Conclusions: There seems to be a high contact reaction rate in patients with oral lichen planus, which is not related to contact with synthetic dental materials. However, further investigations on a larger population with the introduction of additional tests administered 7 days after exposure are required to confirm the effects of delayed hypersensitivity reactions on patients with OLP exacerbation.
\end{abstract}

Key words: oral lichen planus, hypersensitivity, patch tests, oral pathology, contact dermatitis, allergens.

\section{Introduction}

Lichen planus (LP) is a chronic autoimmune inflammatory disease affecting the skin, nails, scalp, genital and oral mucosa. Oral lichen planus (OLP) affects up to $2.2 \%$ of the population, mostly middle-aged people, with a higher prevalence in women. Up to $60 \%$ of patients with cutaneous LP develop oral lesions, but only about $15 \%$ of patients with OLP present skin involvement [1-3]. The disease aetiology remains unknown; however, T-cell triggered apoptosis of oral epithelium basal cell keratinocytes is involved in the pathogenesis [1, 4]. Numerous factors such as stress, dental materials, infectious agents (e.g., hepatitis C virus), drugs, autoimmunity, diabetes mellitus and hypertension have been suggested as triggers for the lesions [2, 4, 5].
Oral manifestations of LP may present as papular, reticular, erosive, atrophic bullous lesions or plaque-like lesions usually involving bilaterally buccal, lingual and gingival mucosa $[3,5]$. As no causative treatment of OLP is available, the management of the disease includes the elimination of predisposing factors, the use of topical corticosteroids, immunomodulators, retinoids, and the application of laser therapy $[1,3,5,6]$.

Oral lichenoid lesions (OLL) clinically and histologically resemble OLP but have identifiable aetiology and appear unilaterally. The most common factors associated with OLL are exposures to dental materials (especially amalgam), drugs (non-steroidal anti-inflammatory drugs and angiotensin-converting enzyme inhibitors) and graft-versus-host disease (GVHD) [5, 7-9]. OLL triggered by direct contact

Address for correspondence: Barbara Dorocka-Bobkowska, Department of Gerodontology and Oral Pathology, Poznan University of Medical Sciences, Poznan, Poland, e-mail: bdorocka@ump.edu.pl, b.dorocka@gmail.com Received: 15.04.2021, accepted: 4.05.2021. 
with restorative materials is considered to be a delayed contact hypersensitivity reaction (type IV according to Gell and Coombs' classification). To distinguish OLP from OLL, skin patch testing may be used as an additional tool in the diagnosis of atypical and treatment-resistant OLP [10-12].

Patch testing (PT) is a standard procedure used to diagnose contact allergy resulting from type IV hypersensitivity. It was first introduced at the end of the $19^{\text {th }}$ century and Josef Jadassohn as well as Bruno Bloch are considered as pioneers, hence the reference to PT as the JadassohnBloch technique. PT is performed by applying potential allergens under occlusion on the skin under standardized conditions. Test substances are prepared in various suitable vehicles such as petrolatum, water, hydrophilic gel, or solvents. The patch tests are applied to the upper back of the patient for $48 \mathrm{~h}$. The reactions are checked initially after 48 and then within 72-96 h. According to the recommendations of the European Society of Contact Dermatitis, PT should be performed in patients presenting with contact dermatitis (including dermatitis related to occupation), but also mucous membrane eruptions in which delayed-type hypersensitivity is suspected [13].

\section{Aim}

This study was designed to investigate the prevalence of delayed hypersensitivity reactions in patients with OLP and identify the most common allergens that may exacerbate the disease.

\section{Material and methods}

Twenty patients diagnosed with OLP and undergoing treatment in the Gerodontology and Oral Pathology Department of the Poznan University of Medical Sciences were enrolled in this study. Subjects were referred to the above Department by their dentists or general practitioners when they presented with white non-removable lesions or/and burning mouth sensation. Patients with lesions which were due to contact with amalgam restorations, and who did not sign the informed consent form were excluded.

A detailed oral examination consisting of anamnesis and clinical evaluation was performed on all recruited subjects. The patients' history included age, gender, subjective complaints related to the oral cavity, dental hygiene habits, addictions, and use of prosthetic appliances. Oral cavity examinations were performed in artificial light with a dental mirror by a qualified dental specialist. All patients underwent skin examination performed by a dermatologist in the Dermatology Department of the Poznan University of Medical Sciences. PT included the Polish Baseline Series and Dental Screening Series, the list of test substances is presented in Tables 1-3. PT were performed by applying haptens into Finn Chambers which were then mounted onto the normal skin of the back for $48 \mathrm{~h}$. The PT reading was performed after 48 and $72 \mathrm{~h}$, in accordance with the International Contact Dermatitis Research Group recommendations (Tables 1-3).

\section{Results}

The study group comprised 18 women and two men with an average age of 63 years (range: $42-88$, SD 11.53 years). The mean duration of the disease was 3 years and 9 months (range: $0.5-21$ years). Eight (40\%) patients presented reticular OLP, an equal number of patients suffered from atrophic/erosive OLP, in 3 (15\%) cases, the co-occurrence of atrophic/erosive and desquamative gingivitis was noticed, and only 1 woman had a plaque-like type OLP. Fourteen (70\%) subjects used denture appliances, and only $2(10 \%)$ smoked tobacco. Thirteen (65\%) patients reported subjective complaints such as burning sensation and pain. Half of the studied population presented positive reactions to the patch tests. A total of 18 contact sensitization reactions were confirmed in 10 female patients. Table 4 shows the distribution of positive $\mathrm{PT}$ reactions according to the clinical type of OLP (Figure 1).

Table 1. Test substances used in the Polish Baseline Series until February 2020

\begin{tabular}{lll}
\hline Benzocaine & Methylisothiazolinone & Lanolin alcohol \\
\hline Cobalt(II) chloride hexahydrate & Neomycin sulfate & $\begin{array}{l}\text { Methylisothiazolinone }+ \\
\text { methylchloroisothiazolinone }\end{array}$ \\
\hline Sesquiterpene lactone mix & Nickel(II) sulfate hexahydrate & Lyral \\
\hline Colophonium & P-phenylenediamine (PPD) & Quaternium-15 \\
\hline Epoxy resin & Potassium dichromate & Budesonide \\
\hline Fragrance mix I & Peru balsam & Tixocortol-21-pivalate \\
\hline Formaldehyde & 4-tert-butylphenolformaldehyde resin (PTBP) & Methyldibromo glutaronitrile \\
\hline $\begin{array}{l}\text { N-Isopropyl-N-phenyl-4- } \\
\text { phenylenediamine (IPPD) }\end{array}$ & Paraben mix & Fragrance mix II \\
\hline 2-Mercaptobenzothiazole (MBT) & Thiuram mix & Sodium tetrachloropalladate(II) hydrate \\
\hline Mercapto mix & 2-Methoxy-6- $n$-pentyl-4-benzoquinone & Propolis \\
\hline
\end{tabular}


Table 2. Test substances used in the Polish Baseline Series since February 2020

\begin{tabular}{lll}
\hline Caine Mix III & Methylisothiazolinone & Lanolin alcohol \\
\hline Cobalt(II) chloride hexahydrate & Neomycin sulfate & $\begin{array}{l}\text { Methylisothiazolinone }+ \\
\text { methylchloroisothiazolinone }\end{array}$ \\
\hline 2-Hydroxyethyl methacrylate & Nickel(II) sulfate hexahydrate & Hydroperoxides of limonene \\
\hline Colophonium & P-phenylenediamine (PPD) & Quaternium-15 \\
\hline Epoxy resin, & Potassium dichromate & Budesonide \\
\hline Fragrance mix I & Peru balsam & Tixocortol-21-pivalate \\
\hline Formaldehyde & Hydroperoxides of Linalool & Methyldibromo glutaronitrile \\
\hline Gentamicin sulfate & Paraben mix & Fragrance mix II \\
\hline 2-Mercaptobenzothiazole (MBT) & Thiuram mix & Sodium tetrachloropalladate(II) hydrate \\
\hline Hydroxyisohexyl 3-cyclohexene & Textile dye mix & Propolis \\
carboxaldehyde & & \\
\hline
\end{tabular}

Table 3. Test substances used in the Dental Screening Series

\begin{tabular}{|c|c|c|c|c|}
\hline Methyl methacrylate & Potassium dichromate & Formaldehyde & Drometrizole & $\begin{array}{l}\text { Ammonium } \\
\text { hexachloroplatinate(IV) }\end{array}$ \\
\hline $\begin{array}{l}\text { Triethylene glycol } \\
\text { dimethacrylate }\end{array}$ & Mercury & 4-Tolyldiethanolamine & $\begin{array}{l}\text { Tetrahydrofurfuryl } \\
\text { methacrylate }\end{array}$ & Benzoylperoxide \\
\hline Urethane dimethacrylate & $\begin{array}{l}\text { Cobalt(II) chloride } \\
\text { hexahydrate }\end{array}$ & $\begin{array}{l}\text { Copper(II) sulfate } \\
\text { pentahydrate }\end{array}$ & Tin & Menthol \\
\hline $\begin{array}{l}\text { Ethylene glycol } \\
\text { dimethacrylate }\end{array}$ & $\begin{array}{l}\text { 2-Hydroxyethyl } \\
\text { methacrylate }\end{array}$ & Methylhydroquinone & Titanium & Epoxy resin \\
\hline $\begin{array}{l}\text { Bisphenol A glycerolate } \\
\text { dimethacrylate (BIS-GMA) }\end{array}$ & $\begin{array}{l}\text { Gold }(I) \text { sodium } \\
\text { thiosulfate dihydrate }\end{array}$ & Palladium(II) chloride & Vanadium & Peru balsam \\
\hline N,N-Dimethyl-4-toluidine & $\begin{array}{l}\text { Nickel(II) sulfate } \\
\text { hexahydrate }\end{array}$ & $\begin{array}{l}\text { Aluminium(III) chloride } \\
\text { hexahydrate }\end{array}$ & Molybdenum & Carvone \\
\hline Benzophenone-3 & Eugenol & Camphoroquinone & Tungsten & $\begin{array}{l}\text { 2,2-bis(4-(2-Methacryl-oxyethoxy) } \\
\text { phenyl)propane (BIS-EMA) }\end{array}$ \\
\hline $\begin{array}{l}\text { 1,4-Butanediol } \\
\text { dimethacrylate }\end{array}$ & Colophonium & $\begin{array}{l}\text { Dimethylaminoethyl } \\
\text { methacrylate }\end{array}$ & Ferric chloride & Glutaral \\
\hline $\begin{array}{l}\text { Bisphenol } \\
\text { A dimethacrylate (BIS-MA) }\end{array}$ & $\begin{array}{l}N \text {-Ethyl- } p \text { - } \\
\text { toluenesulfonamide }\end{array}$ & $\begin{array}{l}\text { 1,6-Hexanediol } \\
\text { diacrylate }\end{array}$ & Silver nitrate & $\begin{array}{l}\text { Sodium tetrachloropalladate(II) } \\
\text { hydrate }\end{array}$ \\
\hline
\end{tabular}

Table 4. The distribution of positive PT reactions according to the clinical type of OLP

\begin{tabular}{lcc}
\hline Variable & $\boldsymbol{N}(\%)$ & $\begin{array}{c}\text { Patch test positive } \\
\text { reactions } \\
n(\%)\end{array}$ \\
\hline Total & $20(100)$ & $10(50)$ \\
\hline Reticular & $8(40)$ & $5(62.5)$ \\
\hline Atrophic/erosive & $8(40)$ & $3(37.5)$ \\
\hline $\begin{array}{l}\text { Atrophic/erosive }+ \\
\text { desquamative gingivitis }\end{array}$ & $3(15)$ & $2(66.7)$ \\
\hline \begin{tabular}{l} 
Plaque-like \\
\hline
\end{tabular} & $1(5)$ & 0 \\
\hline
\end{tabular}

There were only 4 positive patch test reactions after $48 \mathrm{~h}$. During the skin assessment, $72 \mathrm{~h}$ after the test application, an additional 14 positive responses were found. The results of positive reactions after 48 and $72 \mathrm{~h}$ are presented in Table 5.

Some participants displayed more than one positive patch test reaction. The most frequently identified contact allergens in patients with positive patch test reactions were nickel (5) fragrance mix I (2) and gold (2).

Five patients had a positive reaction to only one test substance, four to 2-3 allergens, and only one to more than three allergens (Figure 2). 


\section{Discussion}

The clinical manifestations of contact allergy in oral and perioral diseases may present a broad spectrum of symptoms including cheilitis, stomatitis, perioral dermatitis, lichenoid lesions and even burning mouth syndrome $[9,14]$. In this study, $50 \%$ of the examined patients had at least one positive reaction in PT, which is in agreement with studies performed by Yiannias et al. and Issa et al. $[15,16]$. An even higher rate of positive responses to contact allergens in patients with OLP, namely $75 \%$ was presented by Kim et al. [17].

Many previous studies documented a strong association of OLL with amalgam restorations. The incidence of positive patch test reactions to amalgam compounds in several studies varied from $9.9 \%$ up to $65 \%$ and depended on the direct contact of the affected oral mucosa with the restorations [12, 14, 16, 18-20]. In patients with OLL, the replacement of amalgam fillings led to the resolution of the mucosal lesions. The improvement also depended on the topographical relationship between lesions and restorations. Lesions in complete contact with amalgam healed in $63 \%$ to $97 \%$ of cases, whereas in the case of partial contact, only about $27 \%$ of patients benefitted [12, 16, 18]. However, it was ineffective in patients with OLP due to the disease's autoimmune background $[15,16,18-20]$. Moreover, Laeijendecker et al. found no positive patch test reactions to mercury in patients with concomitant cutaneous LP and Dunsche et al. reported a weak effect of amalgam replacement in a group with concomitant cutaneous LP $[12,18]$. In our study, only 1 patient retained a positive reaction to mercury, despite the removal of amalgam many years before. On the other hand, she showed no positive response to any other applied allergens, including other amalgam metals such as copper or tin. The low rate of positive amalgam patch

Table 5. Positive PT reactions after 48 and $72 \mathrm{~h}$

\begin{tabular}{lcccc}
\hline Parameter & \multicolumn{2}{c}{$48 \mathrm{~h}$} & \multicolumn{2}{c}{$72 \mathrm{~h}$} \\
\cline { 2 - 5 } & $n$ & $\%$ & $n$ & $\%$ \\
\hline Nickel sulfate & 1 & 5 & 5 & 25 \\
\hline Fragrance mix I & 0 & 0 & 2 & 10 \\
\hline Fragrance mix II & 0 & 0 & 1 & 5 \\
\hline Neomycin sulfate & 0 & 0 & 1 & 5 \\
\hline Methylisothiazolinone & 0 & 0 & 1 & 5 \\
\hline Lyral & 0 & 0 & 1 & 5 \\
\hline Methyldibromo glutaronitrile & 0 & 0 & 1 & 5 \\
\hline Balsam Peru & 0 & 0 & 1 & 5 \\
\hline Gold sodium thiosulfate & 1 & 5 & 2 & 10 \\
\hline Mercury & 1 & 5 & 1 & 5 \\
\hline Carvone & 1 & 5 & 1 & 5 \\
\hline 2 hydroxyethyl methacrylate & 0 & 0 & 1 & 5 \\
\hline
\end{tabular}

Figure 1. The white striae (A) and an erosion (B) on the buccal mucosa in a 72-year-old female patient allergic to the mercury

response may result from the inclusion of only OLP patients in our study. Likewise, Kim et al. and Raap et al. reported a low incidence of delayed mercury hypersensitivity in the OLP population [17, 21].

Nickel in stainless steel is one of the most common contact allergens worldwide. It is widely utilized in the household environment, e.g. in jewellery, watches, keys, clothing and kitchen accessories. Delayed type of hypersensitivity to nickel is found in $13 \%$ of the general adult population, and $8.6 \%$ of patients with contact dermatitis react positively to this allergen [22-24]. A retrospective analysis conducted in the Dermatology Department of the Poznan University of Medical Sciences showed a 56\% nickel hypersensitivity reaction among patients with positive patch test results, corresponding to $18 \%$ of the studied population [25]. Similar outcomes were described in the studies of Polish population groups in Lodz (24\%) and Bialystok (21\%) [26, 27]. A recent multicentre study conducted in six European clinics revealed nickel sensitization in $25 \%$ of the studied population $(n=906)$ and excluded the association of OLL with nickel and palladium

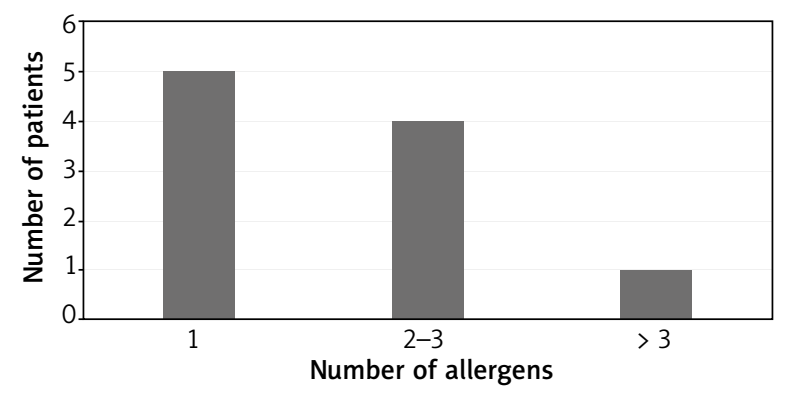

Figure 2. Positive PT reaction in patients with OLP 
sensitization [28]. Our results which showed a positive patch response in $50 \%$ of the test group and $25 \%$ of the studied population confirmed those observations. In dentistry, nickel alloys ( $\mathrm{Ni}-\mathrm{Cr}$ ) are widely used in fixed prosthodontic appliances, metal and porcelain-fused-to-metal crowns and bridges, especially in developing countries [29]. Ahlgren et al. reported a similar rate of nickel hypersensitivity in their study, although this metal is not used in Sweden, except for orthodontics [19]. Likewise, Kim et al. and Rai et al. described a similar positive reaction to nickel sulfate and also to potassium dichromate [14, 17]. On the other hand, we failed to confirm any allergic reaction to chromium both as the metal and as metal ions.

Gold is another frequently identified metal allergen affecting dental patients with positive patch test reactions. Marell et al. reported the hypersensitivity to gold sodium thiosulphate in $50 \%$ of OLL patients with contact hypersensitivity (19.3\% of the whole OLL subgroup) and $17 \%$ of OLP patients with contact hypersensitivity ( $8 \%$ of the entire OLP subgroup), which is in agreement with Khamayasi' and our results [20, 30]. A slightly more frequent reaction among OLP patients was described by Kim et al. (33\% of the whole OLP population and $44 \%$ of those with contact allergy) and Raap et al. (22\% of OLP population) [17, 21]. In other studies conducted on subjects with OLL, the positive patch test response to gold ranged from $3.3 \%$ up to $29 \%$ of the subjects [30-35].

Fragrances, as ingredients of cosmetics, are considered one of the most common contact allergens worldwide [36]. They are also found in medication, food flavourings, household and washing detergents. Studies conducted in various Polish centres revealed contact hypersensitivity to fragrance mixtures in $8.3-20.4 \%$ of subjects, which is consistent with our results [25, 27, 37]. Larsen et al. reported positive PT reactions among 14.3\% of patients with OLP and OLL in line with Torgerson et al., who described fragrance contact allergy in $17.1 \%$ of patients with lichenoid lesions and subjects with cheilitis and burning mouth syndrome [34, 38]. On the other hand, this was not supported by Budimir et al., who observed fragrance hypersensitivity only in patients with perioral dermatitis [31]. Similarly, Polańska et al. presented a case report of a 66-year-old female with papular and erythematous lesions in the upper and lower lip regions, who had both allergic and toxic reactions to fragrances (fragrance mix I and II and Lyral) [39].

Acrylates and methacrylates polymerize in ultraviolet light (or spontaneously) and are widely used in the production of plastics, textiles, glass fibres and artificial nails. Before the popularization of artificial nails, contact allergy to acrylates was considered an occupational disease mainly affecting dental personnel and orthopaedic surgeons. In dentistry, acrylates are present in dentures, composite resins, bonding materials and glass-ionomers [40-45]. Ramos et al. reported $30.3 \%$ of positive patch test reactions attributable to methacrylate, and 10.8\% of the positive responses were related to the use of the acrylic dentures [40]. Muttardi et al. found 2-hydroxyethyl methacrylate to be the most common allergen among methacrylates and cyanoacrylates in their study, similar to Ramos et al. and Aalto-Korte et al. [40-42]. In our study, only 1 patient had a positive reaction to 2 -hydroxyethyl methacrylate among all methacrylates tested, which supports their findings.

Although the skin assessment is commonly conducted 48 and 72-96 $\mathrm{h}$ after PT application, some authors suggest the use of additional tests due to delayed reactions $[13,46,47]$. Allergens generally associated with late positive responses are nickel, gold, mercury, cobalt, chromium, and neomycin [48]. Laeijendecker et al. showed that $35 \%$ of positive patch test responses occurred after 5 to 18 days [12]. Ahlgren et al. reported 26 additional positive allergic reactions seen only on day 7 , which was a $25.2 \%$ increase and was statistically significant [48]. This observation may explain the difference between positive allergic response after 48 and $72 \mathrm{~h}$ in our study, however it has to be emphasized that each patient is informed about the necessity of an additional consultation in case of the appearance of a new skin reaction within the testing area.

The main limitation of this study is a relatively small sample size due to time-consuming test assessments, and the multiple visits, which were very challenging for the patients during COVID-19 pandemic.

\section{Conclusions}

This study has presented a high rate of contact allergic reactions in patients with OLP. It appears to be the first study to report the association between OLP and contact allergy in the Polish population. Further investigations on a larger group with the introduction of additional tests on day seven are required to confirm the influence of delayed hypersensitivity reactions on patients with OLP exacerbation.

\section{Conflict of interest}

The authors declare no conflict of interest.

\section{References}

1. Farhi D, Dupin N. Pathophysiology, etiologic factors, and clinical management of oral lichen planus, part I: facts and controversies. Clin Dermatol 2010; 28: 100-8.

2. Cheng YS, Gould A, Kurago Z, et al. Diagnosis of oral lichen planus: a position paper of the American Academy of Oral and Maxillofacial Pathology. Oral Surg Oral Med Oral Pathol Oral Radiol 2016; 122: 332-54.

3. Canto AM, Müller H, Freitas RR, Santos PS. Oral lichen planus (OLP): clinical and complementary diagnosis. An Bras Dermatol 2010; 85: 669-75. 
4. Nogueira PA, Carneiro S, Ramos-e-Silva M. Oral lichen planus: an update on its pathogenesis. Int J Dermatol 2015; 54: 1005-10.

5. Scully C, Carrozzo M. Oral mucosal disease: lichen planus. Br J Oral Maxillofac Surg 2008; 46: 15-21.

6. Ślebioda Z, Dorocka-Bobkowska B. Low-level laser therapy in the treatment of recurrent aphthous stomatitis and oral lichen planus: a literature review. Adv Dermatol Allergol 2020; 37: 475-81.

7. Kamath VV, Setlur K, Yerlagudda K. Oral lichenoid lesions a review and update. Indian J Dermatol 2015; 60: 102.

8. Rotim Z, Bolanca Z, Rogulj AA, et al. Oral lichen planus and oral lichenoid reaction: an update. Acta Clin Croat 2015; 54: 516-20.

9. Lugović-Mihić L, Ilić I, Budimir J, et al. Common allergies and allergens in oral and perioral diseases. Acta Clin Croat 2020; 59: 318-28.

10. Suter VG, Warnakulasuriya S. The role of patch testing in the management of oral lichenoid reactions. J Oral Pathol Med 2016; 45: 48-57.

11. Klimańska M, Żmudzińska M, Jenerowicz D, CzarneckaOperacz M. The importance of exposure to contact allergens in patients with allergic contact dermatitis. Adv Dermatol Allergol 2011; 28: 203-11.

12. Laeijendecker R, Dekker SK, Burger PM, et al. Oral lichen planus and allergy to dental amalgam restorations. Arch Dermatol 2004; 140: 1434-8.

13. Johansen JD, Aalto-Korte K, Agner T, et al. European Society of Contact Dermatitis guideline for diagnostic patch testing - recommendations on best practice. Contact Dermatitis 2015; 73: 195-221.

14. Rai R, Dinakar D, Kurian SS, Bindoo YA. Investigation of contact allergy to dental materials by patch testing. Indian Dermatol Online J 2014; 5: 282-6.

15. Yiannias JA, el-Azhary RA, Hand JH, et al. Relevant contact sensitivities in patients with the diagnosis of oral lichen planus. J Am Acad Dermatol 2000; 42: 177-82.

16. Issa Y, Duxbury AJ, Macfarlane TV, Brunton PA. Oral lichenoid lesions related to dental restorative materials. Br Dent J 2005; 198: 361-72.

17. Kim TW, Kim WI, Mun JH, et al. Patch testing with dental screening series in oral disease. Ann Dermatol 2015; 27 : 389-93.

18. Dunsche A, Kästel I, Terheyden H, et al. Oral lichenoid reactions associated with amalgam: improvement after amalgam removal. Br I Dermatol 2003; 148: 70-6.

19. Ahlgren C, Axéll T, Möller H, et al. Contact allergies to potential allergens in patients with oral lichen lesions. Clin Oral Investig 2014; 18: 227-37.

20. Mårell L, Tillberg A, Widman L, et al. Regression of oral lichenoid lesions after replacement of dental restorations. J Oral Rehabil 2014; 41: 381-91.

21. Raap U, Stiesch M, Reh H, et al. Investigation of contact allergy to dental metals in 206 patients. Contact Dermatitis 2009; 60: 339-43.

22. Almutairi N, Almutawa F. Allergic contact dermatitis pattern in Kuwait: nickel leads the pack. In-depth analysis of nickel allergy based on the results from a large prospective patch test series report. Adv Dermatol Allergol 2017; 34: 207-15.

23. Czarnobilska E, Obtułowicz K, Wsołek K, et al. Mechanisms of nickel allergy. Przegl Lek 2007; 64: 502-5.

24. Łańczak A, Choręziak A, Płocka M, et al. Nickel-free environment - dreams vs. reality: everyday utilities as a source of nickel and cobalt for patients sensitized to these metals. J Med Sci 2019; 88: 150-5.

25. Marciniak A, Hasse-Cieślińska M, Jenerowicz D, CzarneckaOperacz M. Analysis of standard patch test results performed in patients hospitalized in the Department of Dermatology, University of Medical Science in Poznań from 2003-2005. Adv Dermatol Allergol 2008; 25: 49-54.

26. Kieć-Świerczyńska M, Kręcisz B, Chomiczewska D, Sobala W. Trends in allergy to the 10 most frequent contact allergens in patients examined at the Nofer Institute, Lodz, Poland in 1996-2009. Adv Dermatol Allergol 2012; 29: 19-24.

27. Reduta T, Bacharewicz J, Pawłoś A. Patch test results in patients with allergic contact dermatitis in the Podlasie region. Adv Dermatol Allergol 2013; 30: 350-7.

28. Muris J, Goossens A, Gonçalo M, et al. Sensitization to palladium and nickel in Europe and the relationship with oral disease and dental alloys. Contact Dermatitis 2015; 72: 286-96.

29. Lu Y, Chen W, Ke W, Wu S. Nickel-based ( $\mathrm{Ni}-\mathrm{Cr}$ and Ni-Cr-Be) alloys used in dental restorations may be a potential cause for immune-mediated hypersensitivity. Med Hypotheses 2009; 73: 716-7.

30. Khamaysi Z, Bergman R, Weltfriend S. Positive patch test reactions to allergens of the dental series and the relation to the clinical presentations. Contact Dermatitis 2006; 55: 216-8.

31. Budimir J, Mravak-Stipetić M, Bulat V, et al. Allergic reactions in oral and perioral diseases-what do allergy skin test results show? Oral Surg Oral Med Oral Pathol Oral Radiol 2019; 127: 40-8.

32. Sharma R, Handa S, De D, et al. Role of dental restoration materials in oral mucosal lichenoid lesions. Indian J Dermatol Venereol Leprol 2015; 81: 478-84.

33. Suter VG, Warnakulasuriya S. The role of patch testing in the management of oral lichenoid reactions. J Oral Pathol Med 2016; 45: 48-57.

34. Torgerson RR, Davis MD, Bruce AJ, et al. Contact allergy in oral disease. J Am Acad Dermatol 2007; 57: 315-21.

35. Ahlgren C, Bruze M, Möller H, et al. Contact allergy to gold in patients with oral lichen lesions. Acta Derm Venereol 2012; 92: 138-43.

36. Nardelli A, Carbonez A, Ottoy W, et al. Frequency of and trends in fragrance allergy over a 15 -year period. Contact Dermatitis 2008; 58: 134-41.

37. Klimańska M, Żmudzińska M, Jenerowicz D, CzarneckaOperacz $\mathbf{M}$. The importance of exposure to contact allergens in patients with allergic contact dermatitis. Adv Dermatol Allergol 2011; 28: 203-11.

38. Larsen KR, Johansen JD, Reibel J, et al. Oral symptoms and salivary findings in oral lichen planus, oral lichenoid lesions and stomatitis. BMC Oral Health 2017; 17: 103.

39. Polańska A, Silny W, Czarnecka-Operacz M, Jenerowicz D. Allergic and toxic reaction caused by fragrances - a case report. Adv Dermatol Allergol 2010; 27: 511-4.

40. Ramos L, Cabral R, Gonçalo M. Allergic contact dermatitis caused by acrylates and methacrylates: a 7-year study. Contact Dermatitis 2014; 71: 102-7.

41. Muttardi K, White IR, Banerjee P. The burden of allergic contact dermatitis caused by acrylates. Contact Dermatitis 2016; 75: 180-4.

42. Aalto-Korte K, Alanko K, Kuuliala O, Jolanki R. Methacrylate and acrylate allergy in dental personnel. Contact Dermatitis 2007; 57: 324-30. 
43. Dorocka-Bobkowska B, Medynski D, Prylinski M. Recent advances in tissue conditioners for prosthetic treatment: a review. Adv Clin Exp Med 2017; 26: 723-8.

44. Dorocka-Bobkowska B, Düzgüneş N, Konopka K. AmBisome and Amphotericin B inhibit the initial adherence of Candida albicans to human epithelial cell lines, but do not cause yeast detachment. Med Sci Monit 2009; 15: 262-9.

45. Gebremedhin S, Dorocka-Bobkowska B, Prylinski M, et al. Miconazole activity against Candida biofilms developed on acrylic discs. J Physiol Pharmacol 2014; 65: 593-600.

46. Gawkrodger DJ, Paul L. Late patch test reactions: delayed immune response appears to be more common than active sensitization. Contact Dermatitis 2008; 59: 185-7.

47. Jonker MJ, Bruynzeel DP. The outcome of an additional patch-test reading on days 6 or 7 . Contact Dermatitis 2000; 42: 330-5.

48. Ahlgren C, Isaksson M, Möller H, et al. The necessity of a test reading after 1 week to detect late positive patch test reactions in patients with oral lichen lesions. Clin Oral Investig 2014; 18: 1525-31. 